\title{
LA NACIONALIZACIÓN DE LOS HIDROCARBUROS BOLIVIANOS EN LA PRESIDENCIA DE EVO MORALES AYMA
}

\author{
Rosío Vargas Suárez*
}

RESUMEN: Analiza la nacionalización de la industria de los hidrocarburos de Bolivia en la gestión del presidente Evo Morales con miras a buscar posibles lecciones para México. Se parte del proceso de privatización de la industria desde la década de los ochenta para luego abordar su reversión en el año 2006, a partir de la construcción del andamiaje jurídico y algunas de las políticas que lo acompañaron. Avanzamos a la situación actual caracterizada por una oposición al gobierno del presidente Morales que alienta y promueve acciones de desestabilización. Los conflictos repercuten negativamente en el desempeño de la industria de hidrocarburos, lo cual podría ser aprovechado por los opositores para revertir la "nacionalización" que con dificultad avanza.

Palabras ClaVe: Nacionalización de los hidrocarburos, Distribución de la renta, Acciones de desestabilización.

ABSTRACT: It analyses the nationalization of the industry of hydrocarbons in Bolivia looking for possible lessons for Mexico. It departs from the privatization process of the industry during the eighties to approach its reversion in 2006, from the construction of the legal scaffolding and some of the strategies that accompanied it. We advanced to the present situation characterized by an opposition who encourages and promotes destabilization actions toward the government. The conflicts repel negatively in the performance of the firm which could be taken by opponents to revert the "nationalization" that with difficulties advances.

KEY WORD: Nationalization of hydrocarbons, Distribution of the rent, Actions of destabilization.

* Centro de Investigaciones sobre América del Norte-UnAM (rvargas@servidor.unam.mx). Deseo agradecer la colaboración en la realización de este artículo al Dr. Saúl Escalera, ex gerente de Industrialización de la Empresa Yacimientos Petrolíferos Fiscales de Bolivia. 


\section{ANTECEDENTES}

Bolivia registra tres nacionalizaciones de la industria petrolera a lo largo de su historia. Una en 1937, la segunda en 1969 y, la que es objeto de nuestro análisis, en 2006. Desde los años ochenta se observa toda una serie de antecedentes legales que da cuenta de un gradual proceso de privatización que se va armando, caracterizado por disposiciones a partir de las cuales el Estado cede derechos sobre la industria y recursos a las corporaciones privadas transnacionales. En el caso de la empresa Yacimientos Petrolíferos Fiscales de Bolivia (YPFB) que había sido la fuente de ingresos más importante del Estado hasta 1985, y tuvo una posición relevante en la economía boliviana, el proceso se refleja de manera muy clara.

Después vinieron otras medidas tendientes a lo mismo impulsadas por el presidente Víctor Paz Estensoro (1985-1989), y más tarde Gonzalo Sánchez de Lozada (1993-1997) quien acabó de entregar los sectores estratégicos a las compañías transnacionales apoyándose en leyes para el efecto. A él se le atribuyen la Ley de Capitalización (No. 1544), la Ley de Hidrocarburos (No. 1689), la Ley de Regulación Social, y las modificaciones en la Legislación Tributaria (Ley 843), que legitimaron la entrega de activos, instalaciones y reservas probadas de gas y petróleo a las empresas transnacionales. ${ }^{1}$ El proceso de privatización ocurrió mediante la puesta en marcha de normas, leyes, decretos, reglamentos y varios "anexos" poco conocidos que sirvieron para legalizar la virtual entrega, de forma gratuita, a las empresas extranjeras en lo que son los dos procesos fundamentales de la industria: $1^{\circ}$ la exploración y explotación; $2^{\circ}$ la refinación, el transporte, el almacenamiento y la comercialización.

En este proceso la participación del Banco Mundial fue medular. La dificultad de los pagos de la deuda externa del gobierno boliviano fue el

\footnotetext{
${ }^{1}$ Víctor Rodríguez-Padilla, con la colaboración de Judith Pérez, "Marco legislativo y contractual de las operaciones de la Industria de los hidrocarburos en América Latina y su impacto en la generación de la renta petrolera. Repsol FPFB y la creación de riqueza en Argentina, Bolivia, Ecuador, Perú y Venezuela", Estudio preparado para OxfamRepsol (mimeo), México, 18 de marzo, 2008, p. 4.
} 
argumento para que el Banco Mundial (BM) y el Fondo Monetario Internacional (FMI) amparados en Consenso de Washington, impusieran programas de ajuste estructural (reducción de déficit fiscal, traspaso de excedentes de las empresas públicas al tesoro de la nación) encaminados a desestructurar la empresa pública la que, una vez debilitada, se entregó a las corporaciones privadas. ${ }^{2}$ El proceso se concretó en 1993 por parte del Banco Mundial y el gobierno de Gonzalo Sánchez de Lozada, basado en el proyecto de Ley de Hidrocarburos financiado por el propio Banco Mundial. Entre las recomendaciones sugeridas por este organismo estaban que los campos con reservas probadas debían quedar en manos de las empresas privatizadas (capitalizadas). Ejemplo de ello fue el caso de ENRON. En 1994 a invitación del presidente boliviano esta empresa se asocia con YPFB quedando asentado tal convenio en un memorando de entendimiento. Parte de los negocios realizados por Sánchez de Lozada acordados con ENRON fue su participación como intermediario financiero o "bróker" para financiar la construcción de un gasoducto que iría de Río Grande a Brasil. Por su parte las petroleras norteamericanas dieron el visto bueno al proyecto de la Ley de Hidrocarburos; proyecto que fue presentado al Parlamento boliviano un par de años más tarde para su consideración, quien lo aprobó en 1996 bajo la Ley de Hidrocarburos (No. 1689). ${ }^{3}$ En diciembre de ese año Sánchez de Lozada firmó contratos de asociación con ENRON quien pasó de socio a dueño de recursos gasíferos. El dinero que aportó la empresa para ser parte de la asociación, sería manejado por la propia compañía. Así, se pusieron en sus manos los activos tangibles (reservas e infraestructura) e intangibles, entre ellos el atractivo prospecto que representaba el mercado brasileño para las exportaciones del gas boliviano. Además se incluía una cláusula de confi-

2 Marc Gavaldá, Etnocidio petrolero en Bolivia, Theomai, $2^{\circ}$ semestre, núm. 012, Quilmes, Red de revistas científicas de América Latina, El Caribe, España y Portugal, 2008, p. 2 .

${ }^{3}$ En http://www.caf.com/attach/11/default/BoliviaposiblesimpactosLeyHidrocarburos(Jun05), pdf (fecha de consulta: 2 de mayo, 2009). 
dencialidad que prohibía hacer público el contenido del contrato. Todo esto quedó subordinado a la supremacía de las leyes estadounidenses.

La privatización llevada a cabo en este proceso de "capitalización" significó dividir en cuatro empresas a Yacimientos Petrolíferos Fiscales de Bolivia (YPFB) tres de capital mixto (50/50), sociedades anónimas cuya gestión quedó en manos privadas. Entre éstas estaba Chaco (AMOCO); Andina (YPF, Pluspetrol, Perez Companc) y Transredes (ENRON, Shell, British y Petrobras) las que se apropiaron de gasoductos y oleoductos y toda la infraestructura a cambio de promesas de inversión. ${ }^{4} \mathrm{La}$ otra empresa de capital público que permaneció conservó el nombre de YPFB. Dos de las empresas (Andina y Chaco) asumieron las actividades de exploración y producción realizadas hasta entonces por la empresa pública. La tercera empresa mixta Transredes asumió la administración del sistema de gasoductos. En general, lo único que estas empresas aportaron de más fue el capital que luego utilizaron para su propio funcionamiento. En la práctica, esto representó la entrega de las compañías públicas a cambio de la sola promesa de inversión. Con ello las transnacionales lograron el control, dirección y usufructo de todo el patrimonio de Bolivia ${ }^{5}$ dejando a los bolivianos la posibilidad de adquirir capital "accionario", con la idea de convertirlos en "socios" en tanto las grandes corporaciones se hacían cargo del negocio.

${ }^{4}$ Roberto Fernández Terán, "Hidrocarburos: una mirada crítica desde las Ciencias Sociales, Ojo energético", febrero, 2006, p. 7. En http://www.cesu.umss.edu.bo/PH/pdf/ojo2.pdf (fecha de consulta: 12 de mayo, 2009).

${ }^{5}$ Raquel Gutiérrez Aguilar y Duna Mokrani, "Los pasos del gobierno de Evo Morales. Sobre la nacionalización de los hidrocarburos en Bolivia”, Programa de las Américas del IRC, 12 de mayo, 2006, p. 3. En www.iramericas.org (fecha de consulta: 2 de abril, 2009). 


\section{DISTRIBUCIÓN DE RESERVAS POR COMPAÑÍAS}

\begin{tabular}{|l|r|r|r|r|}
\hline & $\begin{array}{l}\text { Gas Natural* } \\
\text { (Trillones de } \\
\text { pies cúbicos) }\end{array}$ & $\begin{array}{l}\text { Gas Natural } \\
\text { Cuota de } \\
\text { mercado }\end{array}$ & $\begin{array}{l}\text { Petróleo** } \\
\text { Millones de } \\
\text { Barriles }\end{array}$ & $\begin{array}{l}\text { Petróleo } \\
\text { Cuota de } \\
\text { mercado }\end{array}$ \\
\hline Maxus Bolivia Inc. & 518 & $9 \%$ & 1374857 & $15 \%$ \\
\hline British Gas & 819 & $15 \%$ & 1137887 & $12 \%$ \\
\hline PETROBRAS & 796 & $15 \%$ & 988547 & $11 \%$ \\
\hline Total Fina Elf & 357 & $14 \%$ & 1047944 & $11 \%$ \\
\hline Exxon Mobil & 352 & $6 \%$ & 758591 & $8 \%$ \\
\hline $\begin{array}{l}\text { Panamericana } \\
\text { Energy }\end{array}$ & 22 & $4 \%$ & 418836 & $0 \%$ \\
\hline Chaco S.A. & 1407 & $26 \%$ & 2032173 & $22 \%$ \\
\hline ANDINA & 254 & $5 \%$ & 1515161 & $16 \%$ \\
\hline $\begin{array}{l}\text { Otras Empresas } \\
\text { TOTAL }\end{array}$ & 5486 & $100 \%$ & 9291631 & $100 \%$ \\
\hline $\begin{array}{l}\text { *Datos al } 1^{\circ} \text { de } \\
\text { enero, 2003 }\end{array}$ & & & & \\
\hline $\begin{array}{l}\text { **Datos al 1 } \\
\text { enero, } 2002\end{array}$ & & & & \\
\hline
\end{tabular}

FuENTE Ministerio de Minería e Hidrocarburos y Yacimientos Petrolíferos Fiscales de Bolivia, en Repsol YPFB, Informe de Intermón Oxfam..., p. 19.

En lo que concierne a la empresa YPFB-residual la Ley 1689 le prohibió, explícitamente, realizar directamente actividades de exploración y producción de petróleo, a menos que lo hiciera a través del otorgamiento de contratos de Riesgo Compartido con empresas privadas nacionales o extranjeras. Esta empresa quedó como una simple oficina administrativa que operaba con recursos de las compañías petroleras, encargada de promocionar inversiones, suscribir contratos y concentrar la producción de gas de los distintos campos para cumplir con los con- 
tratos suscritos con Brasil y Argentina. Si bien el Estado (de jure) seguía siendo el propietario de los yacimientos, otorgaba al contratista el derecho de explorar, explotar, extraer, transportar y comercializar la producción, esto es, en los hechos le otorgaba, en boca de pozo, la propiedad del petróleo extraído. ${ }^{6}$ Lo anterior quedó plasmado de manera clara en los modelos de contrato de riesgo compartido aprobados en el Decreto Supremo 24806, poco antes de que Sánchez de Lozada dejara el poder. Bajo este esquema se firmaron 76 contratos para explotación y producción de hidrocarburos.

Asimismo, se introdujo la modalidad de licitación internacional (Ley 1689) para otorgar áreas a actividades de exploración. Además las compañías podían disponer libremente de la producción, en caso de descubrimiento comercial, excepto que la producción fuera requerida para el mercado interno con la posibilidad de tomar los precios internacionales como base de referencia.

Los cambios legislativos, así como la reforma a la Ley 843 y la promulgación de la Ley 1731, dieron lugar a un nuevo sistema tributario que con el argumento de impulsar las actividades extractivas, dividieron los yacimientos de hidrocarburos en "Existentes" y "Nuevos" a fin de aplicarles una fiscalidad suave. Esto llevó a que algunos campos gaseros fueran reclasificados como nuevos. Con la intención de satisfacer las exigencias de las empresas transnacionales y generar criterios de atracción de capitales se exigió a las empresas menores pagos en regalías. Para ello, se definió una "Regalía Nacional Complementaria" de 13\% para los productores que no se aplicaría a los hidrocarburos nuevos. En vista de que estos últimos tampoco pagarían la participación nacional de $19 \%$, esto les reducía la carga tributaria a un $18 \%$. En el caso de los hidrocarburos existentes estos pagarían una carga de $50 \%$, de la forma

${ }^{6}$ La Ley 1689 a diferencia de la que le precedió (Ley de Hidrocarburos 1194), señala que el Estado es propietario de las reservas de gas, pero no de la producción y de la comercialización de líquidos y de gas, y por lo tanto se le excluye del círculo de la generación, apropiación y uso del excedente. 
en que estaba estipulado en el sistema anterior. Las corporaciones también consiguieron reducir el impuesto a la remisión de utilidades.

Así, además de renunciar el Estado boliviano a todo aumento de la carga tributaria durante el periodo del contrato al conferirle estabilidad al régimen de regalías, con la Ley Hidrocarburos, apoyada por el Banco Mundial, el Estado boliviano perdió el control del mecanismo de regulación y fijación de precios internos dejando con ello el referente de los costos de producción. Esto llevó a debilitar deliberadamente su papel fiscalizador, el cual era ya de por sí precario por ser la de Bolivia la tributación más baja de la región. ${ }^{7}$ El costo resultante de la privatización en el país ha sido estimado en US \$3.2 mil millones, un equivalente al $64 \%$ de la deuda boliviana. Lo que significa que por cada dólar que ingresó por concepto de impuestos y regalías (1996 a 2002) el Estado dejó de percibir otros 2 dólares. ${ }^{8}$

La construcción del andamiaje institucional se tradujo en una subordinación a las corporaciones privadas, evidenciada en la designación de autoridades en el Ministerio de Desarrollo Económico y, posteriormente, en el Ministerio de Hidrocarburos y de YPFB-residual, entidades claramente vinculadas a las empresas transnacionales. Lo anterior, se arropó en un marco jurídico-institucional diseñado para proteger a las corporaciones dejando al Estado en calidad de apéndice de las primeras. ${ }^{9}$

La cereza del pastel colocada por Gonzalo Sánchez de Lozada fue suscribir contratos de garantía con el Organismo Multilateral de Garantías de Inversiones (OMGI) del Banco Mundial. Con el Centro Internacional de Arreglos y Diferencias a Inversiones (CIADI) y con la Corporación de Inversiones Privadas en el Extranjero (OPIC) de Estados Unidos.

En conclusión, si bien según la Ley de 1996 el Estado seguía siendo el propietario de las reservas en el subsuelo, en los hechos las empresas

${ }^{7}$ Intermón-Oxfam, Repsol YPF en Bolivia: una isla de prosperidad en medio de la pobreza, Barcelona, Informe de Intermón Oxfam, mayo, 2004, p. 3.

${ }^{8}$ Ibid., p. 4.

${ }^{9}$ Roberto Fernández, Terán, FMI, Banco Mundial y Estado neocolonial. Poder supranacional en Bolivia, 2a ed., La Paz, Plural Editores, 2004, p. 92. 
transnacionales se quedaron con el derecho absoluto sobre la exploración, explotación, producción, comercialización, venta en el mercado interno y externo, en tanto que las reservas bolivianas de gas natural y petróleo fueron entregadas a las empresas a través de contratos en los cuales la única obligación de las corporaciones se redujo a pagar regalías, sin compartir utilidades; además de haber conseguido la libertad de la exportación de los recursos.

\section{LA NACIONALIZACIÓN}

Varias movilizaciones sociales constituidas por huelgas, bloqueos y represión que daban cuenta del descontento de la población, que conocía bien las enormes ganancias que se habían llevado las transnacionales desde la última privatización en 1996, se conocen en la historia como la "guerra del gas". ${ }^{10}$ El motivo aparente eran las exportaciones de gas natural (una factura de $\$ 5$ mil millones de dólares) que se harían a Estados Unidos y México vía Chile ${ }^{11}$ mismas que generaron protestas entre la población boliviana haciendo desistir a las compañías privadas de su propósito. El aspecto medular estaba vinculado al régimen de propiedad de los recursos más que al hecho mismo de exportar o no el gas. La resultante inmediata fue un alto costo humano ya que por la "guerra del gas" murieron 67 bolivianos y bolivianas y hubo más de 400 heridos, la mayoría de los cuales procedía de El Alto (La Paz). Cientos de personas,

${ }^{10}$ Un referendo realizado en 2004 mostró el amplio respaldo (89\%) a favor de la causa de la nacionalización.

${ }^{11}$ En el tema del gas, lo más probable es que el gobierno no entiende la magnitud de las movilizaciones populares. Por cuarto día consecutivo, el centro de la ciudad de La Paz fue paralizado por miles de personas que salieron a las calles para rechazar el proyecto de exportación de gas natural licuado a mercados norteamericanos por puertos chilenos. El movimiento crece y cada vez se suman más sectores a la protesta que ahora ya no es exclusiva de la sede de gobierno. Osvaldo J. Calle Quiñonez, "El gobierno dispone la militarización de las calles. Guerra del gas; cuarto día de un movimiento que el gobierno no entiende". En www.prensarural.org/bolivia 20031003.htm (fecha de consulta: 28 de marzo, 2009). 
básicamente procedentes de los estratos medios, condujeron una serie de huelgas de hambre en solidaridad con la protesta indígena las que organizaron marchas y bloqueos. Los efectos ulteriores de esas jornadas devinieron en la expulsión del presidente Sánchez de Lozada (Goni) de la Presidencia de la República. Si bien esto logró sacarlo del poder, mostraba que ni la guerra del agua ni la del gas resultaban suficientes para crear las reformas estructurales para modificar realmente las condiciones imperantes. Esto requería de cambios más profundos, si no es que de un modelo político distinto. ${ }^{12}$

Al asumir la presidencia (2005) Evo Morales tenía como uno de sus objetivos en su agenda modificar la Ley de Hidrocarburos, ya que tenía claro el sesgo de la misma a favor de las corporaciones, y no veía beneficio alguno para el Estado en términos de sus ingresos fiscales. De aquí que una de sus primeras propuestas fuera aumentar los royalties a $50 \%$ de los ingresos. ${ }^{13}$ Con la Ley 3058 (mayo de 2005), previa a la nacionalización, daba pasos firmes para una acción más decidida para modificar las reglas del juego con las transnacionales. Desde esta Ley se fueron preparando las condiciones para la refundación de YPFB a partir de la recuperación de las acciones de las empresas capitalizadas administradas por las Administradoras de Fondos de Pensiones, así como la posibilidad de retomar toda la cadena productiva de la industria de manera directa. ${ }^{14} \mathrm{~A}$

${ }^{12}$ Chris Sweeney, From Rightist Chaos to Leftist Constitutionalism: The Institutionalization of Bolivian Populism, Washington, Council of Hemispheric Affairs, 23 de enero, 2009, p. 6. En www.coha.org/2009/01/from-rightist-chaos-to-leftist-constitutionalism-theinstituti (fecha de consulta: 25 de marzo, 2009).

${ }^{13}$ Joseph Taves, Stuck in the Middle: Bolivia's Gas Crisis, Washington, Council on Hemispheric Affairs, 27 de mayo, 2005, pp. 3 y 4. En www.coha.org/2005/05/stuck-in-themiddle-bolivias-gas-crisis/ (fecha de consulta: 26 de marzo, 2009).

${ }^{14}$ Esta Ley estableció la migración obligatoria de los contratos de riesgo compartido a modalidades nuevas establecidas en esta Ley. Se creo el "Impuesto Directo a los Hidrocarburos", de 32\% sobre el total de la producción de hidrocarburos, aplicado a la producción en boca de pozo. Sumado a las regalías y otros impuestos, podía representar una carga fiscal superior a $50 \%$ del valor de la producción de hidrocarburos. Las estimaciones de los que se podría recuperar por este concepto se estimaba en alrededor de 573 millones de dólares generando una recaudación adicional de 286 millones para el sector público. 
tres meses de su toma de posesión, el presidente Morales anuncia la nacionalización de la industria de hidrocarburos. En mayo de 2006 expide el Decreto de Nacionalización (28701) a través del cual el Estado recupera la propiedad, posesión y el control total y absoluto de los recursos de hidrocarburos. Basado en argumentos jurídico-políticos retoma el control y dirección de la producción, transporte, refinación, almacenaje, distribución, comercialización e industrialización del gas natural y el petróleo de Bolivia. En su parte resolutiva los argumentos jurídicos del decreto establecen que el Estado recupera la propiedad, posesión, y el control total y absoluto de estos recursos. Con ello, las empresas petroleras quedaron obligadas a entregar toda la producción de YPFB, y a trasladar sus contratos hacia otras formas que cumplieran con requisitos legales constitucionales como la licitación pública. Así con base en el Decreto Supremo 24.806 (de 1997) se aprueba el Modelo de Contrato de Riesgo Compartido para Áreas de Exploración y Explotación por Licitación Pública.

En lo que concierne a YPFB, éste asumiría la actividad de comercialización de los hidrocarburos ${ }^{15}$ con lo cual tendría la prerrogativa de fijar los precios. ${ }^{16}$ De igual forma se estableció un nuevo régimen tributario durante el periodo de transición de 180 días.

Todo el andamiaje jurídico del Estado boliviano intentó dar un viraje a las leyes de capitalización con la idea de "deshilvanar" el marco construido ad hoc para el despojo previo. La manera en que se hizo fue llevar la disputa al terreno de lo político en la interpretación de la ley, con el fin de eludir las posibles demandas de las corporaciones en los Tribunales Internacionales. ${ }^{17}$ Con la lógica de que fue una nacionalización sin expropiación porque hubo un proceso de privatización sin la venta de la empresa pública, sólo se "nacionalizaron" las acciones para que el Estado asumiera el control de 50\% más una de las empresas transnacionales con base en el monto de las inversiones. De aquí que el proceso se

\footnotetext{
${ }^{15}$ Rodríguez-Padilla, op. cit., p. 6.

${ }^{16}$ Gutiérrez Aguilar, op. cit., p. 2.

${ }^{17}$ Ibid., p. 3.
} 
podría considerar más bien como una estatización de la propiedad de las acciones, de su propiedad nominal más que una nacionalización en el sentido de recuperar infraestructura y todos los activos. Al no involucrar la expropiación de éstos, la nacionalización se restringió a: 1) establecer mayores impuestos; 2) renegociar contratos con las compañías privadas y; 3) la reconstrucción de las compañías de petróleo y gas del Estado. Todo con la voluntad de establecer nuevas relaciones con las corporaciones transnacionales.

En el primer caso, tasar con mayores impuestos para las compañías petroleras y contratos renegociados la nueva ley retendría el $18 \%$ en royalty y añadiría un $32 \%$ por concepto de Impuesto Directo a los Hidrocarburos IDH, para los mayores campos gaseros o los que producen más de 100 millones de pies cúbicos diarios de gas; el decreto añadió un 32\% adicional para beneficiar a YPFB, durante el tiempo que los contratos fuesen negociados. Esto dejaba un $18 \%$ de los recursos de las ventas del gas a las compañías extranjeras.

En el caso de la renegociación de contratos, con los términos del decreto de nacionalización las compañías extranjeras al operar en Bolivia debían renegociar sus contratos en noviembre de 2006 o dejar el país. En esas condiciones se renegoció con la empresa francesa TOTAL, la Argentina (YPF) y con Petrobras de Brasil. Se puso en evidencia el ejercicio de la capacidad de negociación del Estado boliviano. Las autoridades bolivianas suponían que era poco probable que las transnacionales salieran de Bolivia tras la medida, debido a la cantidad de inversión realizada por las mismas. Pero, como era de esperarse, hubo disgusto entre las empresas privadas, que amenazaron con congelar sus inversiones en el país, cerrar los campos de producción pequeños en el corto plazo argumentando la inviabilidad de sus inversiones con el nuevo régimen fiscal propuesto en la Ley 3058.

Entre mayo y noviembre de 2006 se negociaron 44 contratos con 12 compañías diferentes, mismos que entraron en operación en mayo de 2007. En este último año el proceso de nacionalización había significado para YPFB tomar $100 \%$ de las acciones de Petrobras a partir de la empresa 
Bolivia-Refinación S. A.; de convertirse en accionista mayoritario de Andina S. A. y del Chaco S. A.; asumir 100\% de las acciones de CLHB; y $97 \%$ de las acciones de Transredes S. A. En el caso de REPSOL la nacionalización se tradujo en un contrato de traspaso de acciones firmado entre YPFB, que recuperaría 51\% y, REPSOL YPF, que compartiría la administración de Andina. ${ }^{18}$

El porqué no se tomaron medidas más radicales resulta comprensible a la luz de las necesidades financieras y de inversión del Estado boliviano, de su decisión de no acudir al financiamiento de las instituciones financieras internacionales, una vez que recuperara su industria. Sin embargo, también podría haber respondido a la voluntad de las corporaciones transnacionales de permanecer en el país, dado el momento de la industria petrolera de las naciones desarrolladas caracterizada por una declinación de reservas probadas, que las lleva a procurar garantizar su permanencia en los sectores corriente arriba de las naciones productoras. Al ser Bolivia el segundo país más importante en reservas gasíferas probadas, después de Venezuela, este interés en permanecer en el país, resulta comprensible. Si bien las empresas estaban interesadas en revisar sus contratos presionando por un atractivo margen de ganancias, difícilmente se retirarían del país, ya que saben lo que les puede ofrecer esta industria en Bolivia. De acuerdo a uno de los directivos de REPSOL (empresa española-estadounidense), Roberto Mallea, "por cada dólar que se invierte, la ganancia es de 10". Esto en buena medida obedece a los bajos costos de producción del gas boliviano $0.97 \mathrm{cvs}$ de dólar frente a los costos de países como Venezuela, México y Argentina. ${ }^{19}$

${ }^{18}$ Marc Gavaldá, "Industria española en América Latina: impactos en el medio ambiente y en las economías de la región”, Periódico Diagonal, 11 de junio, 2008, p. 2. En http:/www.diagonal periodico.net/Los-malabarismos-de-repsol-ypf (fecha de consulta: 12 de abril, 2009).

${ }^{19}$ Edgar Ramos Andrade, Paraíso energético del neoliberalismo. Bolivia: potencia gasifera, sin embargo no administra ese recurso, Bolivia, Aporrea.org, 24 de marzo, 2009, p. 4. En http://www.aporrea.org/imprime/a4866.html (fecha de consulta: 20 de mayo, 2009). 
En lo que concierne a la reconstrucción de las compañías del Estado en el nivel de YPFB los cambios que se generaron fueron los siguientes: ${ }^{20}$

- En nombre del Estado se definieron volúmenes, precios y mercados para su producción.

- Se suscribieron dos contratos de exploración y explotación con YPFB-Petroandina SAM.

- Hubo un proceso de valoración de licuables (contrato GSA).

- Mayor participación en megacampos (32\%).

- Un contrato de exportación con ENARSA; y el desarrollo y ejecución de proyectos para el mercado interno y la exportación en toda la cadena a través de las empresas nacionalizadas.

- La refundación de YPFB se hizo con el objeto de operar en toda la cadena de hidrocarburos, lo cual comprende empresas como: Chaco S.A.; Andina S.A., YPFB, Petroandina SAM y YPFB (Transportes S.A.; Refinación S.A.; Logística S.A., Servicios S.A.; Distribución).

- A través de Chaco y Andina, YPFB controla una serie de campos petroleros (40).

- A través del control de TRANSREDES, YPFB controla más de 70\% del sistema de transporte por gasoductos, oleoductos y poliductos. Así también tiene participación en los gasoductos que exporta a Brasil.

- En materia de refinación la nacionalización significó tomar el control y dirección de las dos refinerías existentes en el país: G. Elder Bell y G. Villarroel. Posteriormente se creó YPFB Refinación S. A., para ejercer la administración de las anteriores. Con la nacionalización se aumentó de forma sustantiva la inversión (de US\$ 1380 millones en 2005 a US\$ 33126 en 2008) que se tradujo en una capacidad de procesamiento que se incrementó de 43600 a 47800 bpd.

${ }^{20}$ Entrevista telefónica con el Dr. Saúl Escalera, gerente de Industrialización de YPFB (febrero, 2009). El Dr. Escalera fungió en ese cargo por varios años hasta su retiro en abril del mismo año. 
- La nacionalización de CLHB ${ }^{21}$ implicó retomar el control del almacenaje y transporte por poliductos en toda la cadena de hidrocarburos, estrechamente vinculadas a las refinerías.

Para el 2007 el proceso de recuperación de activos mostraba los siguientes resultados:

- Ampliaciones de gasoductos (Gasoducto al Altiplano Fases II y III y Villamontes Tarija GVT Fases I y II).

- Aumentos en la capacidad de refinación en 1800 bpd.

- Distribución de la renta petrolera: de $18 \%$ en regalías, éstas pasan a $50 \%$.

- Las exportaciones de gas natural aumentan de 1669 millones de US dls. en 2006 a 1989 US dls. en 2007.

- En términos de volumen las exportaciones aumentan de 30.6 millones de metros diarios a 32 millones de metros día.

- En términos de la recaudación fiscal, ésta pasa de 1840 millones de dls. en 2006 a 1972 en 2007.

Todo esto da cuenta de que si bien no hay un crecimiento espectacular de la industria, los indicadores son positivos.

\section{EL DEBATE NACIONAL}

Si bien la nacionalización ha sido un hito importante en el avance del pueblo boliviano hacia la posibilidad de una mayor equidad social, las fuerzas de oposición, tanto nacionales como internacionales, están dificultando el proceso no sólo del gobierno en turno, sino también alcanzan el desempeño productivo de la industria petrolera.

Los resultados positivos de haber recuperado el control del manejo de la industria se pone en evidencia, tanto en términos del aumento en los ingresos resultante de las nuevas políticas como en los mayores precios del gas que se han traducido en mayores ingresos gubernamentales (en nueve

\footnotetext{
${ }^{21}$ Compañía Nacional que abastece el mercado interno de productos petroleros.
} 
veces, de 2002 a 2007), de US\$ 173 millones a un estimado de US\$ 1.57 miles de millones en 2007. Sin embargo, esto resulta en conflictos por el lado de la distribución de la renta petrolera entre diferentes actores económicos que reclaman su derecho.

La disputa regional por los recursos del Impuesto Directo a los Hidrocarburos (IDH) se ha centrado en el uso de los ingresos, que el gobierno de Morales está haciendo al distribuirlos en programas sociales. La distribución ha generado conflictos en el nivel de las distintas entidades departamentales y municipales, fundamentalmente, pero también entre otros actores sociales que quieren acceder a una mayor parte del presupuesto. Los gobernadores opositores de los departamentos orientales y sus simpatizantes ${ }^{22}$ están en contra de la decisión del presidente Morales, de que el gobierno central controle directamente los impuestos de la venta de petróleo y gas, en lugar de ser administrados por las provincias. ${ }^{23}$ En el nivel nacional parte de los recursos son destinados a un programa para proveer de dinero a las familias de cada niño inscrito en la escuela primaria. También hay un fondo de seguro social para la vejez. ${ }^{24}$

Desde el punto de vista de los inversionistas los recursos generados por las ventas de los hidrocarburos deberían destinarse a las inversiones en el sector realizadas por las corporaciones. Ven mal la redistribución de la renta entre los actores sociales, ya que el dinero no se traducirá en inversiones y ulteriores exportaciones. La visión de los empresarios lógicamente no ha sido en apoyo al proceso de nacionalización, aun cuando ésta se encuentra lejos de representar una medida radical y más

22 También son contrarios al plan del presidente Morales de revisar la Constitución con el fin de darle más derechos a los indígenas, que son mayoría poblacional.

${ }^{23}$ Como resultado de la nueva política de petróleo y altos precios para el gas, el ingreso del gobierno boliviano pasó de \$173 millones de dólares en 2002 a un estimado de \$1.57 miles de millones de dólares en 2007. Nueva Política Hidrocarburífera. Regalías y Participaciones, Ministerio de Hidrocarburos y Energía, La Paz, marzo, 2007, p. 2.

${ }^{24}$ Sobre el aspecto de la distribución véase Tina Hodges, "Part II: Political Conflicto ver Gas and Oil Tax Distribution", 2007, p. 6. En http://ain-bolivia.org/index.php?option= com_content\&task=view\&id=109\&Itemid=29 (fecha de consulta: 26 de febrero, 2009). 
bien les ha permitido seguir siendo parte de la industria e incluso, mantener atractivas ganancias.

Las críticas del sector empresarial al gobierno de Evo Morales tienen que ver, obviamente, con intereses afectados, sin embargo han acudido al argumento sobre la forma en que se realizó la nacionalización y el rumbo que ha tomado. Consideran que hubo un innecesario antagonismo por parte del presidente Morales contra los inversionistas extranjeros, al utilizar a las tropas en acciones desafiantes, que sólo consiguieron tensar las relaciones con quienes más tarde se han tenido que sentar a negociar (REPSOL y Petrobras).$^{25}$ Los cuestionamientos mayores al gobierno de Evo Morales apuntan a lo mismo: haber tomado el control de todos los ingresos del gas natural en lugar de distribuirlos entre los gobiernos locales, con quienes se han tensado las relaciones y no desviarlos de una reinversión productiva en la industria. Sobre ésta se destaca una pretendida inestabilidad legal y política resultante de la nacionalización. Por ejemplo, el riesgo que ha tenido el exportador de Gas Natural Licuado (GNL) boliviano ante las dificultades para mantener los compromisos de exportación en el mediano plazo, debido a que como resultado de la nacionalización, la producción boliviana del gas natural ha caído, por lo que no ha podido cubrir las exportaciones a Brasil (Cuiabá) y Argentina, a este último se le han reducido a la mitad. ${ }^{26}$ En el caso de Brasil, esta situación lo ha llevado a modificar su matriz energética a fin de romper su dependencia del gas boliviano para los próximos 15 años. En los hechos esto se ha traducido

${ }^{25}$ El presidente Morales envió tropas a confiscar las instalaciones de Petrobras, Repsol y Total, los principales inversionistas extranjeros en Bolivia. Las gestoras de activos, filiales de bancos españoles y suizos que administraban fondos de pensiones, tuvieron que transferir sus carteras de valores de petroleras a la empresa YPFB. Norman Gall, "Gas en Bolivia: conflictos y contratos”, Revista ARI, núm. 130, Real Instituto Elcano, 2006, p. 1. En http://www.realinstitutoelcano.org/wps/portal/!ut/p/kcxml/04_Sj9SPykssy0xPLMnMz0v M0Y QjzKLN4k3N (fecha de consulta: 25 de mayo, 2009).

${ }^{26}$ Humberto Vacaflor, "Energy and Bad Luck in Bolivia", en Cynthia J., Aronson et al. [ed.], Energy and Development in South America: Conflict and Cooperation, Washington, Woodrow Wilson Center for Scholars-Latin American Program/FLACsO, Secretaría General, Chile, 2008, p. 521. 
en una reducción de las importaciones por parte de Brasil de 30 a 20 (MMCD). ${ }^{27}$ En el caso de Paraguay las exportaciones podrían verse también reducidas debido a los ataques a gasoductos y a la ocupación de las plantas petroleras por parte de los simpatizantes de la oposición al presidente Morales. Toda esta serie de sucesos con origen diverso se está convirtiendo en una incertidumbre productiva por la declinación de sus reservas gasíferas y, por tanto, de su capacidad exportadora.

En el nivel nacional las compañías petroleras cuestionan la gestión del actual mandatario por lo que califican de un pobre desempeño las actividades extractivas en 2008, debido a que para ellos no se han realizado las inversiones esperadas. ${ }^{28}$ En tanto, en el ámbito internacional se da, además, la imagen de una empresa que está sola (YPFB) y que se encuentra en dificultades en un país cada vez más aislado.

Si bien ciertamente en el nivel de la industria nacional todo esto ha repercutido sobre la producción gasera de Bolivia y, en consecuencia, sobre su capacidad exportadora, la intencionalidad de los comentarios en la prensa internacional tienen sentido a la luz de las presiones para dar marcha atrás a la nacionalización y conseguir una mayor apertura en la industria de los hidrocarburos a las empresas transnacionales. La estrategia de desestabilización y las maniobras que alientan la balcanización en el país, irían también en ese sentido.

La expulsión del embajador de Estados Unidos, Phillipe Goldberg, el 11 de septiembre de 2008 da cuenta de la intromisión del gobierno estadounidense al apoyar y alentar a las fuerzas de oposición a Morales en las provincias orientales del país, conflictos que terminaron en una matanza de 17 campesinos, de acuerdo al gobierno boliviano.

De nueva cuenta el 28 de noviembre de 2008 el gobierno de Morales acusó a la Central de Inteligencia de Estados Unidos (CIA) de involucra-

${ }^{27}$ AFP, "Bolivia pide a Brasil definir volumen de gas que comprará en el futuro", Prensa Libre. com, 23 de marzo, 2009, p. 1. En http://www.prensalibre.com/pl/2009/marzo/23/ 090323195355.1zp0gvaj.html (fecha de consulta: 20 de mayo, 2009).

${ }^{28}$ La cámara boliviana de hidrocarburos destaca que en 2008 sólo se perforaron 4 pozos. 
miento en un intento de golpe de Estado contra su gobierno durante los meses de agosto y septiembre. Ante estos sucesos la reacción de Washington no se hizo esperar. La respuesta fue la descertificación de Bolivia, en diciembre de 2008, acompañada de la negación de las preferencias comerciales de que había disfrutado con la Ley Andina de Preferencias Comerciales y la Ley de Fortalecimiento antidrogas (ATPDEA por sus siglas en inglés) aduciendo una supuesta no cooperación en la guerra antidrogas. ${ }^{29}$

Las estrategias de desestabilización han tomado otras formas como el asentamiento de tropas estadounidenses en este caso, en Paraguay (junio de 2005 por un periodo de 18 meses). ${ }^{30}$ Ésta fue una acción realizada con el argumento de entrenar militares paraguayos para hacer frente a la lucha contra el terrorismo. El temor de los bolivianos estribaba en que ésta podría ser la excusa para controlar los recursos petroleros y de gas natural en su territorio, ya que muy cerca de donde se establecería esta base se encuentra la región de Tarija, una de las regiones más ricas en reservas de petróleo y gas natural. ${ }^{31}$ Además estaba la posibilidad de un asentamiento permanente. Si bien Washington declaró esta acción como temporal, hay semejanzas en la manera en que se desarrolló la base de Manta en Ecuador que tuvo su origen en un establecimiento pretendidamente temporal, que luego terminó siendo una base militar.

${ }^{29}$ Guy Hursthouse, Bolivia: Evo Morales Moves to Centre Stage for Historic January 25th Referendum, Washington, Council on Hemispheric Affairs, 21 de enero, 2009, p. 4. En www.coha.org/2009/01 bolivia-evo-morales-moves-to centre-stage-for-historic-jan (fecha de consulta: 23 de marzo, 2009).

${ }^{30}$ ABC Color, "Base Militar de EUA en Paraguay despierta inquietud en Bolivia", Asunción, 6 de julio, 2005. En www.abc.com.py/sección.php?sec=7\&fec=2005-07-06 (fecha de consulta: 20 de marzo, 2009). "Contingente militar llega a Paraguay", 2 de julio, 2005. En http://bolivia.indymedia.org/gn/2005/07/20520.shtml (fecha de consulta: 20 de marzo, 2009).

${ }^{31}$ Luis Chaquetilla, sindicalista boliviano ha señalado que Washington ha lanzado una intervención militar a través de países vecinos con el objetivo específico de controlar las reservas gaseras. Véase Mary Donohue y Melissa Nepomiachi, Washington secures Long-Sought Hemispheric Outpost, Perhaps at the Expense of Regional Sovereignty, Washington, Council on Hemispheric Affairs, 22 de julio, 2005, p. 4. En www.coha.org/2005/07washington-secures-long-sought-hemispheric-outpost-perh (fecha de consulta: 26 de marzo, 2009). 
La administración del presidente Barack Obama apunta a continuar las políticas de su antecesor, si bien con tintes de mayor diplomacia. ${ }^{32}$ En este sentido son elocuentes las declaraciones de personeros del departamento de Estado, James Steinberg, en el sentido de oponer un frente a Venezuela y Bolivia por considerar "que persiguen políticas que no sirven a los intereses de su gente o de la región". ${ }^{33}$ Las declaraciones de su secretaria de Estado, Hillary Clinton, dan también cuenta de la continuidad del tono duro del gobierno de George W. Bush, defensora de los beneficios de las corporaciones y descalificadora del nacionalismo latinoamericano. Al considerar que la agenda bilateral con Bolivia, al igual que con cualquier país, se diseña con base en sus intereses y percepciones ${ }^{34}$ no se puede pensar en giros radicales de lo que hasta ahora ha sido la política hacia Bolivia. Uno de los argumentos socorridos por la actual secretaria de Estado para cuestionar al gobierno del presidente Morales se refiere precisamente a la democracia, pese a la contundencia electoral con la que el presidente Morales llegó al poder. En este sentido, Clinton ha señalado que "la democracia debe nutrirse al interior con moderación y construir instituciones democráticas; no puede imponerse por la fuerza desde fuera", ${ }^{35}$ lo que está dando pauta para justificar acciones intervencionistas. Detrás, están los intereses en los enormes yacimientos gaseros de Bolivia y, ahora de litio, mineral estratégico para la fabricación de las baterías de los autos eléctricos; que se vislumbran importantes para el futuro de la humanidad.

${ }^{32}$ Howard and Roger Hollander, Bolivia: Hillary Clinton and James Steinberg ¿Talk Tough? On Latin America, Washington, Council on Hemispheric Affairs, February, 4, 2009 , p. 2. En www.coha.org/2009/02/bolivia-hillary-clinton-and-james-steinberg$\%$ e2\%80\%9cta (fecha de consulta: 26 de marzo, 2009).

${ }^{33}$ Hollander, op. cit., p. 2.

34 "La cooperación bilateral con Venezuela y Bolivia sería en el interés mutuo de nuestros respectivos países, por ejemplo, contraterrorismo, antinarcóticos, energía y comercio". Ibid., pp. 3 у 4.

${ }^{35}$ Ibid., p. 6. 


\section{CONCLUSIONES}

El proceso de privatización que vivió Bolivia durante los años ochenta y noventa permite desprender constantes lecciones para México, a partir de las leyes y las políticas con que se van debilitando a las empresas estatales hasta dejarlas en el "punto de privatización". La condición de países en vías de desarrollo y el sometimiento a reformas estructurales, por parte de los organismos financieros internacionales, tras crisis económicas, financieras o problemas de endeudamiento, también han sido condicionantes de políticas encaminadas a la privatización de los sectores energéticos de los países que las viven. Las estrategias para dividir y fraccionar a las empresas estatales es parte de este manejo de los centros de poder. La construcción del andamiaje jurídico-institucional con que gradualmente se desmantelan los estados, forman parte de la experiencia. El paralelismo del caso boliviano con los procesos que han vivido otros países, en particular México, resulta elocuente.

Otro aspecto a destacar es que el hecho de privatizar toda la cadena de la industria petrolero-gasera, hace que la propiedad de los recursos se convierta en un elemento que relativiza la importancia de la propiedad. Aun cuando de jure el Estado boliviano siempre mantuvo dicha propiedad, el control real se puso en entredicho al quedar las actividades extractivas, productivas y de distribución en manos de las corporaciones transnacionales.

La "nacionalización" a medias de Bolivia, en el sentido de que fue más bien un proceso de renegociación de contratos y de mayor fiscalidad para el Estado, ilustra las dificultades que enfrentó y sigue enfrentando el país para recuperar el manejo soberano de sus recursos. Los obstáculos para salir adelante dan cuenta no sólo del acoso permanente en que operan las empresas públicas; de las principales tendencias del devenir social y el conflicto de intereses entre los principales actores políticos por la apropiación y distribución de los recursos procedentes de la venta y exportaciones del gas natural. La derecha boliviana enarbola banderas secesionistas tratando de sustraerse de las directrices de la Federación 
para no perder los históricos privilegios de que han gozado, sobre todo en el caso de los departamentos ubicados en los sitios de localización de los principales yacimientos gaseros del país. Ante este panorama la pregunta que surge es ¿cuánto tiempo más podrá continuar el Estado boliviano manejando su industria de hidrocarburos de forma soberana?

Una posible respuesta tendría que considerar una evaluación de los pilares en que se sostiene el gobierno del presidente Morales: 1) una sociedad politizada y el apoyo de diversos grupos como los sindicatos, los agricultores pero, sobre todo el sector indígena; 2) pese a que el país tiene una historia de intervenciones militares, las fuerzas armadas están siendo leales al presidente y no han mostrado interés en enfrentarlo; 3 ) en el nivel internacional su alianza con el eje petrolero (Venezuela, Rusia e Irán), sobre todo con Venezuela tanto por la amistad personal con el presidente Hugo Chávez, como por el apoyo militar que este último le ha brindado. La pertenencia de Bolivia al ALBA que puede ser definitiva por el apoyo regional y la solidaridad de países afines a su proyecto. Otro factor importante es su ubicación geográfica (el Cono Sur) y su lejanía relativa de Estados Unidos, lo que le permite un mayor margen de maniobra.

La permanencia en el poder del presidente Morales es condición sine qua non para el mantenimiento de YPFB como empresa pública en vista del poder de las fuerzas opositoras, que buscan una mayor apertura de la misma al capital privado. Las políticas hasta ahora propuestas por la administración en turno apuntan en la dirección correcta para hacer de Bolivia no sólo una potencia gasera (a través de su política exploratoria que busca incorporar la mayor cantidad de reservas posibles), por los elevados niveles de producción que tiene proyectado alcanzar (la proyección de la producción para gas natural en el periodo 2008 a 2026 espera alcanzar un máximo de 103.7 MMmcd en el 2017); y por intentar alcanzar una industria energética de punta a partir de añadir valor agregado a sus recursos naturales. Proceso que ya se ha iniciado con la instalación de plantas de licuables y la construcción de plantas petroquímicas. El reto será seguir sacando ventaja de la capacidad de negociación que le confiere su 
enorme potencial gasero y de no permitir la imposición de directrices por parte de los centros financieros, los organismos internacionales y los centros de poder. El presidente Morales combina en su persona una visión pragmática en los negocios, al tiempo que tiene la visión de un político que privilegia el largo plazo lo que con seguridad le hará salir avante en las dificultades que afronta su industria estatal de hidrocarburos.

Recibido: 7 de mayo, 2009. Aceptado: 30 de agosto, 2009. 
BIBLIOGRAFÍA COMPLEMENTARIA

\section{LIBROS}

Camacho GonzÁlez S. et al., Nacionalización del siglo XXI: 111 años de historia petrolera en Bolivia, La Paz, Ministerio de Hidrocarburos y Energía, 2007, s/p.

CEDLA, Ley de Hidrocarburos 3058. ¿Recuperación real de los hidrocarburos? (Serie para que no nos mientan. Jan Kárntxapxañanaka sapataki, 2), La Paz, Centro de Estudios para el Desarrollo Laboral y Agrario (CEDLA), 2005, 56 pp.

GANDARILlas, M. y TAHBUd M., Nacionalización de los hidrocarburos en Bolivia: la lucha de un pueblo por sus recursos naturales, Madrid, Icaria, 2009, 151 pp.

MARTínez, ERIK y EsPada JuAn Luis, La gestión de la renta de los hidrocarburos en las prefecturas: caso Tarija, La Paz, Centro de Estudios para el Desarrollo Laboral y Agrario, 2008, 172 pp.

McGuigan, Clare, Los beneficios de la inversión extranjera. ¿Cuáles fueron sus resultados en el sector petrolero y gas en Bolivia?, La Paz, Centro de Estudios para el Desarrollo Laboral y Agrario, 2007, 184 pp.

Rollano Barrero, Mario et al., Introducción a la industria de los hidrocarburos, Santa Cruz de la Sierra, Cámara Boliviana de los Hidrocarburos, 2007, $700 \mathrm{pp}$.

Orgaz García, Mirko, La guerra del gas. Fundamentos histórico-políticos, para la $3^{a}$ Nacionalización de las Transnacionales Petroleras, $3^{\mathrm{a}}$ ed., La Paz, Tribuna boliviana, 2004, 323 pp.

\section{SITIOS RECOMENDADOS}

Pacheco, Hernán Federico, "Perspectivas del escenario petrolero en América Latina 2009. Incrementan los niveles de producción en algunos países de la región", Petróleo, Inelectra, febrero, 2009. Página elec- 
trónica www.petroleo.com/pi/secciones/PI/ES/MAIN/IN/ARTICULO/doc.68299 HTML.html/?idDocumento= (fecha de consulta: 27 de julio, 2009).

http://www.cbh.org.bo Cámara boliviana de hidrocarburos en Santa Cruz de la Sierra

http://www.execlub.net/?cat=2>

http://www.periodicopukara.com/

http://www.aporrea.org 